\title{
Implications of different income diversification indexes: the case of rural
}

\section{China}

\author{
Jianmei Zhao $^{1^{*}} \cdot$ Peter J. Barry ${ }^{2}$ \\ ${ }^{1}$ China Academy of Public Finance and Public Policy, Central University of Finance and Economics, China \\ ${ }^{2}$ Department of Agricultural and Consumer Economics, University of Illinois at Urbana-Champaign, USA
}

Received: 15 January 2013

Revised: 4 February 2013

Accepted: 4 February 2013

\begin{abstract}
This study investigates rural income diversification measures. Applying rural household survey data in China, we utilize OLS and quantile regression to compare the effects from various rural diversification measures on household income. Our results indicate the high importance of using a two-dimensional rather than a one-dimensional measure of diversification in empirical analyses, at least in the rural China case. Among the two-dimensional indexes, the strong consistency of the quantile patterns between income and diversification, and the plausibility of changes in these relationships, suggest that any one of the diversification measures is acceptable in the relevant studies.
\end{abstract}

Keywords: rural income, diversification measure, quantile regression, China

JEL Classification Codes: Q12, Q14

\section{Introduction}

Most rural households in developing countries are undergoing the process of diversifying their income sources. Unlike investment portfolios in finance that diversify for minimizing risks, rural income diversification primarily targets better utilizing the extant production resources and increasing household income. Despite extensive discussion on the motivation or effects of rural income diversification, the extant literature lacks well-established conventions on the use of indicators to capture observed rural income diversification.

*Corresponding author. E-mail: jianmei@cufe.edu.cn.

Citation: Zhao, J. and P.J. Barry (2013) Implications of different income diversification indexes: the case of rural China, Economics and Business Letters, 2(1), 13-20. 
Approaches used to quantify diversification can be divided into two groups. One group contains one-dimensional indexes, which include indicators that count the number of business activities or evaluate changes in the volumes of different divisions. The other group measures diversification based on two dimensions that consider both the number of areas of activities and their relative volumes of turnover. Do these two group diversification measures equally reflect rural diversification? The purpose of this study is to evaluate various diversification measures and provide guidance in choosing the appropriate ones.

\section{Measures of rural income diversification}

In agriculture, one-dimensional attempts to quantify income diversification alternatives available for rural areas have focused on the estimation of non-farm income's share of total household income (Block and Webb, 2001; Davis et al., 2010; Lanjouw, Quizon, and Sparrow, 2001). The assumption in these studies is that a higher share of non-farm income amounts to higher income diversification and less vulnerability to earning shocks from specific sources of revenue. Another branch of studies has adopted one or more of two-dimensional indexes, such as the complement of the Herfindahl-Hirschman index, the Berry index, and the entropy measure of diversification (Mishra, et al., 2010; McNamara and Weiss, 2005).

The above diversification indices can be expressed in the general form developed by Hannah and Kay (1977):

$$
D=\left[\sum_{j=1}^{n} s_{j}^{\alpha}\right]^{1 /(1-\alpha)} \quad \text { for } \alpha \geq 0 \text { and } \alpha \neq 1
$$

where $D$ is the diversification index, $s_{j}$ is the share of the $j^{\text {th }}$ income source, and $n$ is the number of income sources. $\alpha$ represents the diversification parameter that determines the weight of the number of income sources versus the evenness in the distribution of income share. The higher the $\alpha$ value, the greater is the emphasis on the distribution of income shares. The upper limit value of the index for any $\alpha$ value is the number of income sources, and the lowest limit is one. The lower value occurs when a given household has only one source of income, and the upper value occurs only if the shares are equal across all income sources.

Specifically, $\alpha=0$ measures diversification by simply counting the number of income sources. When $\alpha$ approaches 1 , the index becomes the entropy index $\left(D_{\mathrm{E}}\right)$, calculated as $\sum_{\mathrm{j}=1}^{\mathrm{n}} s_{j} \ln \left(1 / s_{j}\right)$. When $\alpha=2$, the index becomes $1 / \sum_{\mathrm{j}=1}^{\mathrm{n}} \mathrm{s}_{\mathrm{j}}^{2}$ or the inverse of the Herfindahl-Hirschman index. The revised format of the Herfindahl-Hirschman index becomes the Berry index, $D_{\mathrm{B}}=1-\sum_{j=1}^{n} s_{j}^{2}$. More recently, Ginevičius (2009) proposes a new diversification indicator $\left(D_{\mathrm{G}}\right)$ that stresses the changes in the number of unrelated income sources. The Ginevičius index is expressed as $D_{\mathrm{G}}=1-\frac{1}{\sum_{j=1}^{n} \frac{1-s_{\max }}{1-s_{j}}}$, with $s_{\max }$ representing the largest income share.

For a rural household with a single income source, $D_{\mathrm{B}}=D_{\mathrm{E}}=D_{\mathrm{G}}=0$, and the larger the value of the diversification index, the greater is the number of diversified income sources in 
the business.

\section{Model and data}

Our focus here is to compare the effects of the respective diversification indexes on a regression of rural household income against diversification and other control variables, in order to determine which index is appropriate to use. OLS and quantile regression are conducted to make the comparisons ${ }^{1}$.

$$
\begin{aligned}
& \mathrm{E}\left(Y_{i} \mid D_{i}, X_{i}\right)=\alpha+\beta D_{i}+\gamma X_{i} \\
& \left(Y_{i} \mid D_{i}, X_{i}\right)=\alpha_{\tau}+\beta_{\tau} D_{i}+\gamma_{\tau} X_{i} \quad \text { where } \quad \tau \in(0,1)
\end{aligned}
$$

where $Y_{i}$ denotes household income from farm and non-farm activities. $D_{i}$ represents rural diversification, $\beta$ and $\beta_{\tau}$ reflect their marginal effects at the mean and at different quantiles $(\tau)$ of household income, respectively. $X_{i}$ is a vector of control variables, including age, gender, education of the household head, labour capacity, production assets, operating land, and the dummy variables representing self-employed business and household locations. Similarly, $\gamma$ and $\gamma_{\tau}$ are their corresponding coefficient vectors.

The data used in this study are from a rural household survey sponsored by the Hongkong and Shanghai Banking Corporation Limited (HSBC), and carried out by Tsinghua University in China. The cross-sectional survey was conducted in 2007 and 2008 with 2,782 household observations spread over 12 provinces in China. Based on the geographical location, the provinces of Inner Mongolia, Liaoning, Jilin, and Heilongjiang are grouped into the northern area; Shandong, Shanxi, Henan, and Shanxi are grouped into the central area; Anhui, Jiangxi, Hubei, and Hunan provinces represent the southern area.

The survey includes information on demographic characteristics of rural households; farm resource endowments (production assets, durable goods holdings and real estate holdings); household income from plant industry, aquaculture and animal husbandry; and income generated from non-farm activities, such as handicraft manufacture, construction and transportation industry, commerce and other services. The variable summary is reported in Table 1.

\footnotetext{
${ }^{1}$ No endogeneity problem occurs between diversification and household income. Diversification affects income, but not the inverse. Wealthier households would concentrate on the lucrative work. Using the county average diversification index as an instrument, our Wu-Hausman test rejects possible endogeneity issue.
} 
Table 1. Summary statistics of regression variables

\begin{tabular}{lccccc}
\hline & Mean & Std & Min & Max & Median \\
\hline Income (10,000 Yuan) & 4.133 & 11.874 & 0.500 & 350.000 & 2.000 \\
One-dimensional diversification & measure & & & & \\
Income source number & 2.136 & 1.038 & 1.000 & 8.000 & 2.000 \\
Non-farm income share & 0.585 & 0.391 & 0.000 & 1.000 & 0.718 \\
Two-dimensional diversification measure & & & & \\
Entropy index & 0.177 & 0.159 & 0.000 & 0.761 & 0.173 \\
Berry index & 0.248 & 0.225 & 0.000 & 0.806 & 0.227 \\
Ginevičius index & 0.422 & 0.331 & 0.000 & 0.871 & 0.512 \\
Control variables & & & & & \\
Household head age & 46.820 & 10.591 & 20.000 & 86.000 & 46.000 \\
Household head gender & 0.068 & 0.252 & 0.000 & 1.000 & 0.000 \\
Education of household head & 7.900 & 3.146 & 0.000 & 18.000 & 9.000 \\
Farm labor capacity & 2.847 & 1.334 & 0.000 & 12.000 & 2.000 \\
Production assets (10,000 Yuan) & 5.806 & 31.359 & 0.000 & 1000.000 & 0.400 \\
Operating land (mu) & 23.126 & 52.039 & 0.000 & 450.000 & 6.000 \\
Self-employed business & 0.036 & 0.187 & 0.000 & 1.000 & 0.000 \\
\hline
\end{tabular}

\section{Empirical results and rural diversification measure in China}

In this section, we first report the regression results and then consider the diversification measurement that better fits China.

\section{Comparison of Diversification Measures}

The OLS and quantile regression coefficients from various diversification measures are plotted in Figure 1.

The horizontal axis of each diagram in Figure 1 represents household income quantile, while the vertical axis shows the scale corresponding to the regression coefficients. The solid and dotted lines that parallel the horizontal axis are OLS coefficients and their $95 \%$ confidence intervals. The kinked dotted lines and their corresponding shaded area stand for the quantile regression coefficients and their $95 \%$ confidence intervals.

Among one-dimensional diversification measures, the OLS estimate from the number of income sources indicates an insignificant sign, while its quantile coefficients display a progressive pattern of positive coefficients below the 75th quantile. Using non-farm income share as the diversification measure yields not only the positive OLS estimate, but also progressive positive coefficients along income quantiles. In summary, the one-dimensional diversification measures predict upward effects of diversification on rural household income.

When rural diversification is measured with the number and the share from each income source, those two-dimensional measures indicate consistent patterns of effects from rural diversification on household income. The OLS estimates from the entropy index, the Berry index, and the Ginevičius index all indicate negative signs, implying that, on average, rural diversification reduces household income. However, the quantile regression discloses that, 
rural diversification actually enhances household income for poor households, the effects of rural diversification disappear for rural households with middle income, and rural diversification imposes progressive and strong negative impacts on households with their income above the median.

The effects from the control variables in regressions with alternative diversification measures are similar (Figure 2). Education of household head, labour capacity, self-employed business, and asset variables positively affect household income along the income quantiles. The age and gender of the household head, and the operating acres impose minor effects on household income.

\section{Which Diversification Index Better Fits China?}

In the context of rural China, the one-dimensional and two-dimensional diversification measures yield contrary results regarding their effects of rural diversification on household income. Which measure better represents rural diversification in China?

Basically, rural diversification reflects rural households' voluntary exchanges of assets and their allocations of assets across various activities in order to achieve their income goals (Barrett et al., 2001). A rising diversification level causes a variation in both the number of earning activities and the distribution across volumes from each component. Counting the number of income sources has meaning only when the income shares are evenly allocated. Meanwhile, using non-farm income share as the diversification measure neglects a number of participated activities; the same amount of non-farm income from a single source and multiple sources will have different implications for rural households.

In China, large rural populations concentrate on lower-pay, easy-entry farm or non-farm work, such as labour-intensive handicrafts. Essentially, rural diversification for low income families involves participation in multiple income-earning activities to generate novel sources of income. A greater number of revenue sources obtained by a household leads to an expanded income. Diversification aims at improving household income. Accordingly, the diversification measure for poor farm families should stress the number of income sources, while the income share seems less important due to their inability to control the job opportunities. Nonetheless, this is not the case for the wealthier households. Rural households with higher incomes are normally capable of undertaking more lucrative work and allocating their family labours to multiple income generating activities to balancing risks. The main purpose of this intended diversification is to diversify business risks, thus the distribution of income shares should give greater weights in the diversification measure. To integrate diversification measures for different types of rural households, two-dimensional diversification measures better fit rural diversification in China. 


\section{Conclusion}

This study investigates rural income diversification measures. Our results indicate the high importance of using a two rather than a one-dimensional measure of rural income diversification in empirical analyses, at least in the rural China case considered here. Among the two-dimensional indexes, the strong consistency of the quantile patterns between income and diversification, and the plausibility of changes in these relationships, suggest that any one of the diversification measures is acceptable in the relevant studies.

Acknowledgements. This research is sponsored by "Humanities and Social Sciences Planning Fund, No: 10YJC790393" from Chinese Ministry of Education. The authors appreciate Hongkong and Shanghai Banking Corporation Limited (HSBC) and School of Economics and Management, Tsinghua University for providing us with the data.

\section{References}

Barrett, C. B., Reardon, T., and Webb, P. (2001) Nonfarm income diversification and household livelihood strategies in rural Africa: concepts, dynamics, and policy implications, Food Policy, 26, 315-331.

Block, S., and Webb, P. (2001) The dynamics of livelihood diversification in post-famine Ethiopia, Food Policy, 26, 333-350.

Davis, B., Winters, P., Carletto, G., Covarrubias, K., Quiñones, E. J., Zezza, A. and DiGiuseppe, S. (2010) A cross-country comparison of rural income generating activities, World Development, 38, 48-63.

Ginevičius, R. (2009) Quantitative evaluation of unrelated diversification of enterprise activities, Journal of Civil Engineering and Management, 15, 105-111.

Hannah, L., and Kay, J. A. (1977) Concentration in modern industry: theory, measurement and the UK experience, Macmillan: London.

Hussain, A., Lanjouw, P., and Stern, N. (1994) Income inequalities in China: evidence from household survey data, World Development, 22, 1947-1957.

Lanjouw, P., Quizon, J., and Sparrow, R. (2001) Non-agricultural earnings in peri-urban areas of Tanzania: evidence from household survey data, Food Policy, 26, 385-403.

McNamara, K. T., and Weiss, C. (2005) Farm household income and on-and off-farm diversification, Journal of Agricultural and Applied Economics, 37, 37-48.

Mishra, A., Erickson, K. W., Harris, J. M., Hallahan, C.B., and Uematsu, H. (2010) Determinants of Farm Household Income Diversification in the United States: Evidence from Farm-Level Data, paper presented at the at the $114^{\text {th }}$ EAAE Seminar "Structural Changes in Agriculture", Berlin, Germany. 

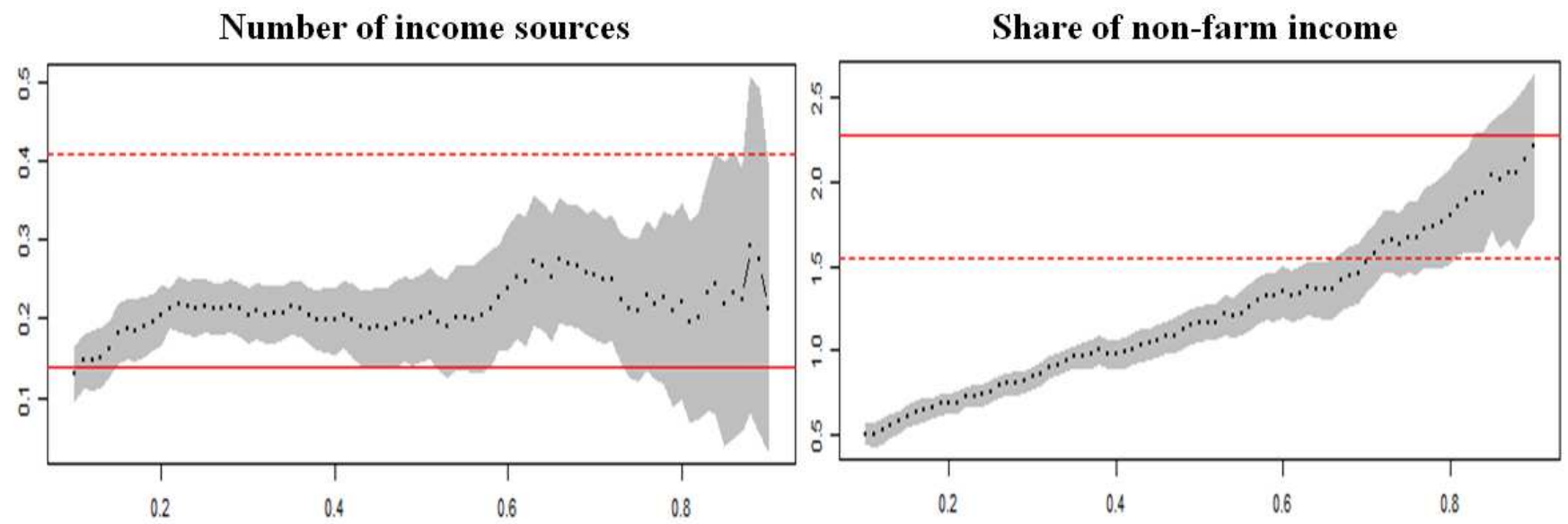

Entropy measure of diversification

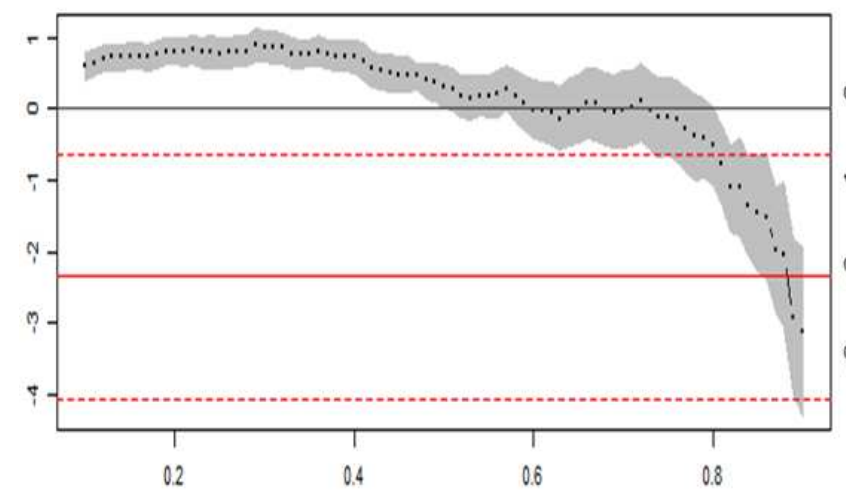

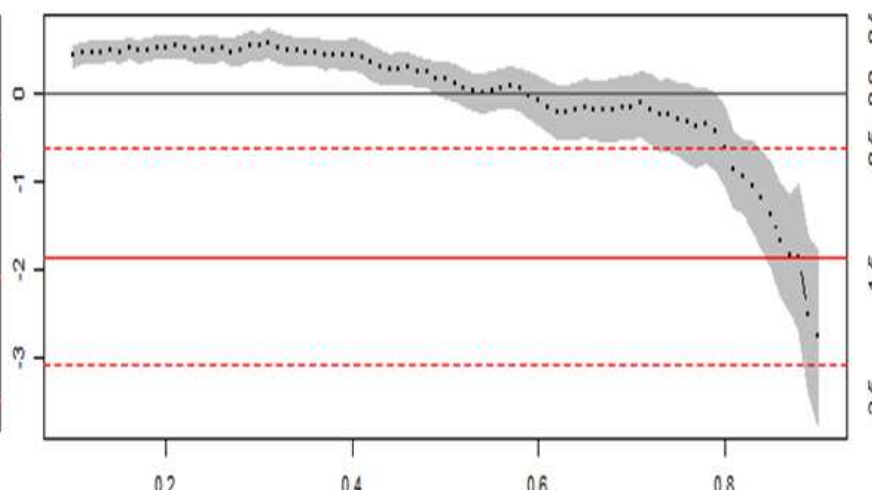

0.2

The Berry index

Figure 1. Effects of various diversification measures on household income
The Ginevičius index

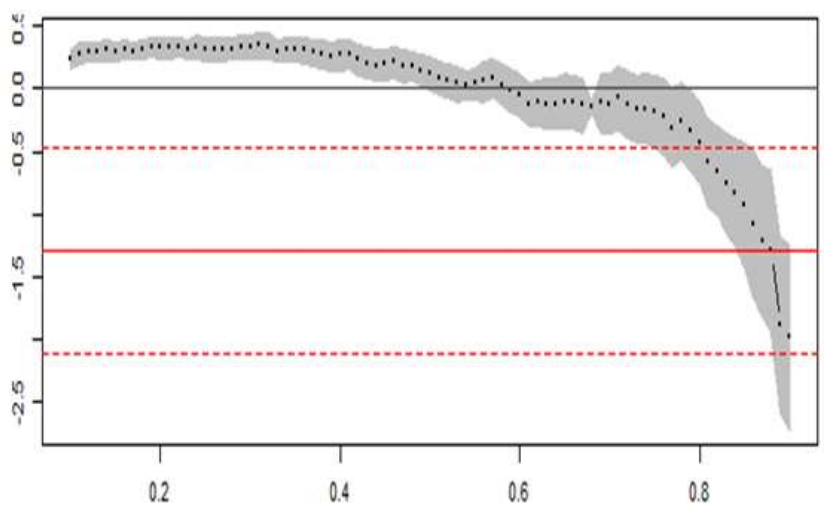



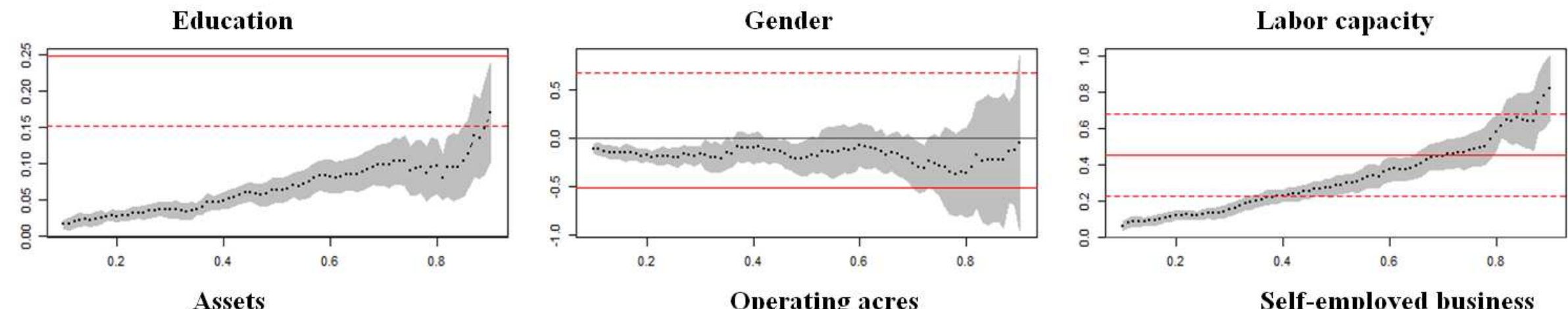

Operating acres

Self-employed business
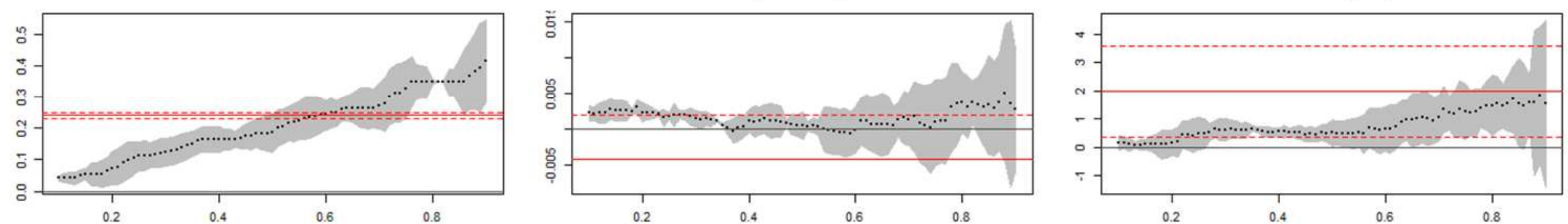

Age

Regon2
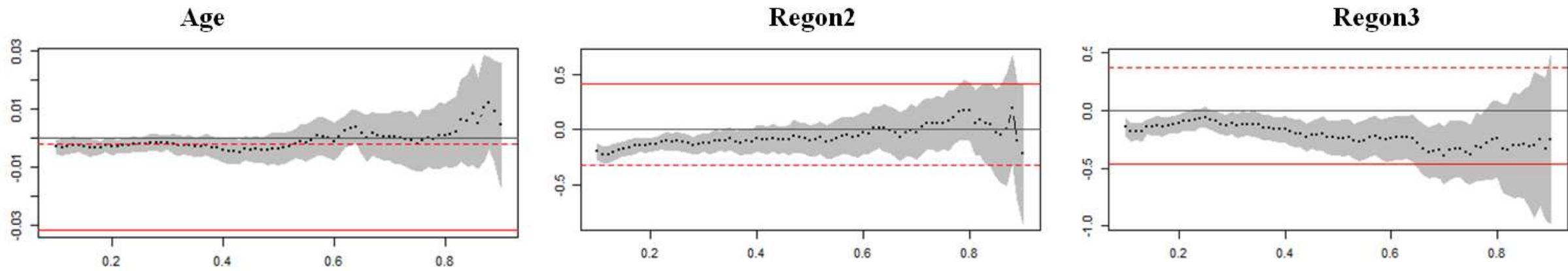

Figure 2. Effects of control variables on household income 